\title{
Unexpected variations in translation initiation machinery
}

Kyungtaek Lim ${ }^{1,2}$, Yoshikazu Furuta ${ }^{1,2}$, Ichizo Kobayashi ${ }^{1,2,3^{*}}$

From Eighth International Society for Computational Biology (ISCB) Student Council Symposium 2012

Long Beach, CA, USA. 13-14 July 2012

\section{Background}

In prokaryotes, the Shine-Dalgarno (SD) sequence in the 5 ' untranslated region (UTR) of mRNA forms a duplex with the anti-Shine-Dalgarno (anti-SD) sequence to initiate translation [1]. The mechanism has been regarded as universal, as the core of the anti-SD sequence (5'-CCTCC3 ', anti-SD motif) is completely conserved in every prokaryote genome according to previous reports [2]. Recent accelerated accumulation of complete genomic sequences motivated us to conduct an updated screening for anti-SD sequence variants.

\section{Results}

By comparison analysis of 1,182 completely sequenced eubacterial genomes, we found fifteen genomes in which no 16S rRNA genes carry the anti-SD motif. Loss of the anti-SD motif in these 'non-anti-SD' genomes is always accompanied by loss of SD-like sequences in 5' UTR.

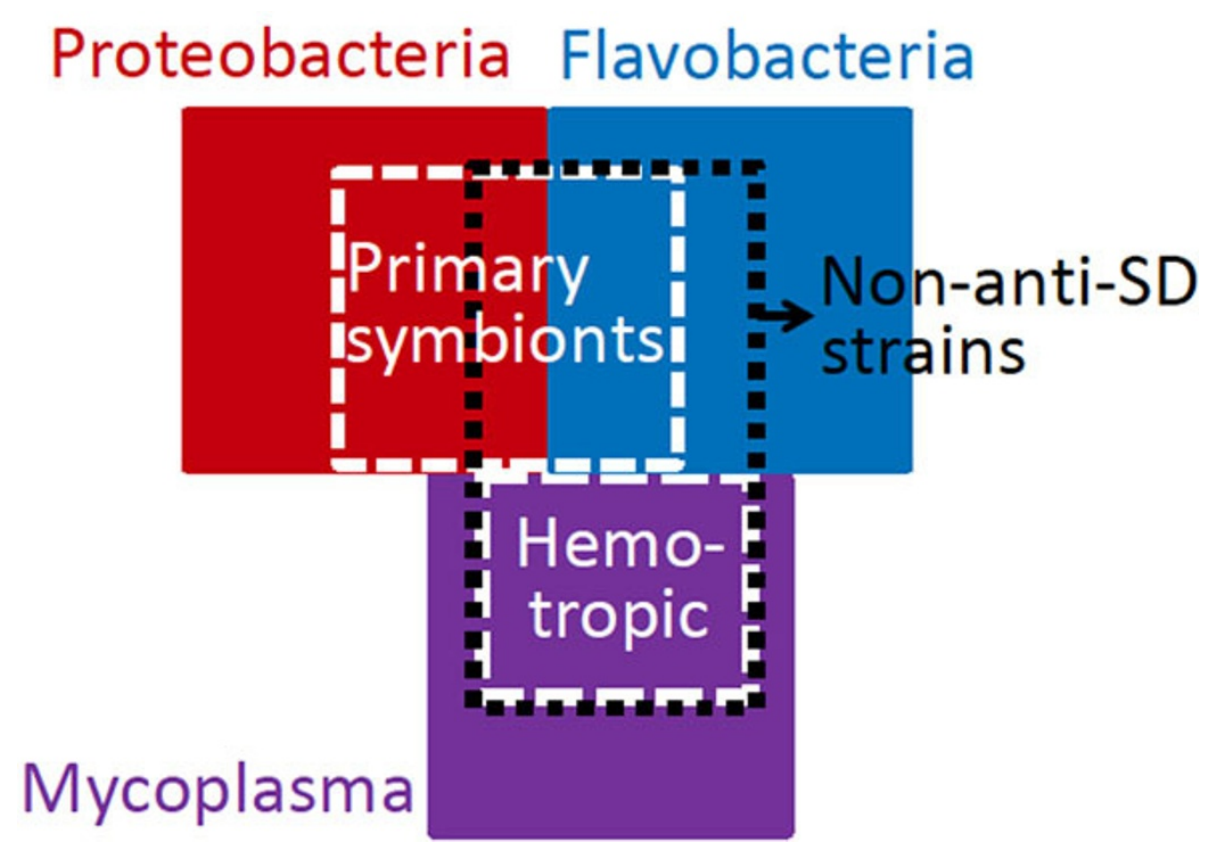

Figure 1 Distribution of the non-anti-SD genomes

\footnotetext{
* Correspondence: ikobaya@ims.u-tokyo.ac.jp

'Department of Medical Genome Sciences, Graduate School of Frontier

Sciences, University of Tokyo, Minato-ku, Tokyo, 108-8639, Japan

Full list of author information is available at the end of the article
}

(c) 2012 Lim et al; licensee BioMed Central Ltd. This is an Open Access article distributed under the terms of the Creative Commons 
These non-anti-SD genomes belong to either the phylum Proteobacteria $(n=3)$, the class Flavobacteria $(n=9)$, or the genus Mycoplasma ( $n=3)$ (Figure 1). Bacteria with extreme association with eukaryotic hosts, such as primary symbionts of insects $(n=9)$ and intracellular parasites $(n=3)$, were prevalent (12 of 15$)$ in the non-anti-SD genomes. Their loss of SD-related features may be related to the massive gene/function decay driven by the host association. All Flavobacteria strains we examined, regardless of anti-SD motif conservation, seem to rarely depend on SD/anti-SD interaction to initiate translation because significant A enrichment in 5' UTR of their genes will not allow the $C$-rich anti-SD sequence to bind. An unknown alternative mechanism that uses the A-rich sequence may play a dominant role for translation initiation in this lineage, resulting in many non-anti-SD genomes that even include free-living bacteria's. In Mycoplasma, only those living in red blood cells (hemotropic mycoplasmas) have lost the anti-SD motif (Figure 1), suggesting that certain environmental factors may have been involved in this loss.

\section{Conclusions}

The non-anti-SD genomes we reported here represent an extreme aspect of the dynamic evolution in the translation initiation mechanisms, strongly indicating extinction of $\mathrm{SD} /$ anti-SD interaction in some bacterial lineages. Attentive analysis of such peculiar genomes led us to suggest likely factors that gave rise to the loss. First, advanced association with eukaryotic hosts and subsequent immense genomic/functional reduction. Second, intra-genomic dominance of SD-independent translation initiation mechanisms. Finally, hemotropic environment.

Our study described here has been published as an original research article [3].

\section{Author details}

'Department of Medical Genome Sciences, Graduate School of Frontier Sciences, University of Tokyo, Minato-ku, Tokyo, 108-8639, Japan. ${ }^{2}$ Institute of Medical Science, University of Tokyo, Minato-ku, Tokyo, 108-8639, Japan.

${ }^{3}$ Department of Biophysics and Biochemistry, Graduate School of Science, University of Tokyo, Minato-ku, Tokyo, 108-8639, Japan.

Published: 14 December 2012

\section{References}

1. Shine J, Dalgarno L: Determinant of cistron specificity in bacterial ribosomes. Nature 1975, 254(5495):34-38.

2. Nakagawa S, Niimura Y, Miura K, Gojobori T: Dynamic evolution of translation initiation mechanisms in prokaryotes. Proceedings of the National Academy of Sciences of the United States of America 2010, 107(14):6382-6387.

3. Lim K, Furuta Y, Kobayashi I: Large variations in bacterial ribosomal RNA genes. Mol Biol Evol 2012, 29:2937-2948.

doi:10.1186/1471-2105-13-S18-A5

Cite this article as: Lim et al:: Unexpected variations in translation initiation machinery. BMC Bioinformatics 2012 13(Suppl 18):A5.

\section{Submit your next manuscript to BioMed Central and take full advantage of:}

- Convenient online submission

- Thorough peer review

- No space constraints or color figure charges

- Immediate publication on acceptance

- Inclusion in PubMed, CAS, Scopus and Google Scholar

- Research which is freely available for redistribution
Ciomed Central 